\title{
Origin of High Efficiency and Long-Term Stability in Ionic Liquid Perovskite Photovoltaic
}

\author{
Lingfeng Chao, ${ }^{1}$ Tingting Niu, ${ }^{1}$ Hao Gu, ${ }^{2}$ Yingguo Yang, ${ }^{3}$ Qi Wei ${ }^{D},{ }^{1}$ Yingdong Xia $\left(D,{ }^{2}\right.$ \\ Wei Hui, ${ }^{2}$ Shouwei Zuo, ${ }^{4}$ Zhaohua Zhu, ${ }^{2}$ Chengjie Pei, ${ }^{2}$ Xiaodong Li, ${ }^{5}$ Jing Zhang, \\ Junfeng Fang, ${ }^{5}$ Guichuan Xing, ${ }^{6} \mathrm{Hai}_{\mathrm{Li}}{ }^{2}$ Xiao Huang, ${ }^{2}$ Xingyu Gao, ${ }^{3}$ Chenxin Ran, \\ Lin Song, ${ }^{1}$ Li Fu, ${ }^{1}$ Yonghua Chen $\mathbb{D}^{1,2}$ and Wei Huang $\mathbb{D}^{1,2,7}$
${ }^{1}$ Frontiers Science Center for Flexible Electronics, Xi'an Institute of Flexible Electronics (IFE) and Xi'an Institute of Biomedical Materials \& Engineering, Northwestern Polytechnical University, 127 West Youyi Road, Xi'an 710072, China
${ }^{2}$ Key Laboratory of Flexible Electronics (KLOFE) \& Institution of Advanced Materials (IAM), Nanjing Tech University (Nanjing Tech), Nanjing, 211816 Jiangsu, China
${ }^{3}$ Shanghai Synchrotron Radiation Facility, Shanghai Institute of Applied Physics, Chinese Academy of Sciences, Shanghai 201204, China
${ }^{4}$ Beijing Synchrotron Radiation Facility, Institute of High Energy Physics, Chinese Academy of Sciences, Beijing 100049, China
${ }^{5}$ School of Physics and Electronic Science, Ministry of Education, Nanophotonics \& Advanced Instrument Engineering Research Center, East China Normal University, Shanghai 200062, China
${ }^{7}$ Key Laboratory for Organic Electronics \& Information Displays (KLOEID) and Institute of Advanced Materials (IAM),
Nanjing University of Posts and Telecommunications, Nanjing, 210023 Jiangsu, China \\ ${ }^{6}$ Institute of Applied Physics and Materials Engineering, University of Macau, Macau, Macao SAR 999078, China
}

Correspondence should be addressed to Yonghua Chen; iamyhchen@njtech.edu.cn and Wei Huang; iamwhuang@nwpu.edu.cn

Received 22 May 2020; Accepted 2 August 2020; Published 10 September 2020

Copyright (c) 2020 Lingfeng Chao et al. Exclusive Licensee Science and Technology Review Publishing House. Distributed under a Creative Commons Attribution License (CC BY 4.0).

\begin{abstract}
Environment-friendly protic amine carboxylic acid ionic liquids (ILs) as solvents is a significant breakthrough with respect to traditional highly coordinating and toxic solvents in achieving efficient and stable perovskite solar cells (PSCs) with a simple one-step air processing and without an antisolvent treatment approach. However, it remains mysterious for the improved efficiency and stability of PSCs without any passivation strategy. Here, we unambiguously demonstrate that the three functions of solvents, additive, and passivation are present for protic amine carboxylic acid ILs. We found that the ILs have the capability to dissolve a series of perovskite precursors, induce oriented crystallization, and chemically passivate the grain boundaries. This is attributed to the unique molecular structure of ILs with carbonyl and amine groups, allowing for strong interaction with perovskite precursors by forming $\mathrm{C}=\mathrm{O} \ldots \mathrm{Pb}$ chelate bonds and $\mathrm{N}-\mathrm{H} \ldots \mathrm{I}$ hydrogen bonds in both solution and film. This finding is generic in nature with extension to a wide range of IL-based perovskite optoelectronics.
\end{abstract}

\section{Introduction}

Perovskite solar cells (PSCs) have attracted extensive attention in emerging photovoltaics with certified efficiency as high as $25.2 \%$ [1-4]. Compared to traditional photovoltaic technologies, such as silicon ( $\mathrm{Si}$ ) solar cells, gallium arsenide (GaAs) solar cells, and cadmium telluride (CdTe), one of the most attractive features of PSC is its solution-processable characteristic [5-8], which is able to remarkably reduce the cost of the process, and it is simple to implement the prepa- ration of flexible devices [9-11]. It is worth noting that, currently, high-quality perovskite film preparation requires a complicated antisolvent method under an inert atmosphere based on N,N-dimethylformamide (DMF) and dimethyl sulfoxide (DMSO) as precursor solvents and chlorobenzene (CB) as an antisolvent [12-18]. In addition to solvent handling issues and toxicology concerns, antisolvent engineering with cumbersome processes requires a higher operating technique and environment, which seriously hinders the commercialization process of PSCs. 
Recently, the breakthrough of solvent application in PSCs is employing novel protic amine carboxylic acid ionic liquids (ILs) as perovskite precursor solvents to replace traditional highly toxic and coordinating solvents [19-27], e.g., DMF and DMSO. ILs have the merits of environment-friendly, stable physical and chemical properties, low vapor pressure, wide electrochemical window, and high solubility [19]. The amine carboxylic acid IL methylammonium formate (MAFa) was first employed as a perovskite precursor solvent, and a large-area, orientationally pure crystalline $\mathrm{MAPbI}_{3}$ film with periodic microarrays and very low trap state density can be fabricated by a sharp liquid-to-solid transition [20]. At the same time, a new IL, methylammonium propionate (MAPa), was also demonstrated to be a novel solvent system for PSCs [22]. Recently, we successfully reported an IL solvent, methylammonium acetate (MAAc), which leads to power conversion efficiency (PCE) over $20 \%$ by a simple one-step method in humidity air without any additive [23]. Moreover, two-dimensional Ruddlesden-Popper PSCs employing IL solvents exhibited a certified PCE close to $18 \%$ with excellent stability [24]. Moreover, the Dion-Jacobson phase and tinbased PSCs based on ILs also showed excellent performance $[26,27]$, suggesting the universal characteristics of IL solvents. ILs are expected to be a promising solvent for the extensive adaptability in the field of perovskite optoelectronic technology and especially for industrial production requiring a simple and fast process. However, the lack of in-depth understanding of ILs on the origin of efficient and stable PSC is challenging the development of IL-based perovskite photovoltaic.

Here, we show that protic amine carboxylic acid ILs are able to combine the three functions of solvents, additive, and passivation into one system to achieve efficient and stable PSCs. Firstly, the ILs have the capability to dissolve a series of perovskite precursors by strong chemical interaction between the solvent and solute. Secondly, ILs can induce oriented crystallization and accelerate the conversion of precursor solution to perovskite crystal by forming active intermediates. Thirdly, the residual ILs in situ chemically passivate the grain boundaries by interacting with undercoordinated $\mathrm{Pb}$ and $\mathrm{I}$. The unique molecular structure of protic amine carboxylic acid ILs is capable of improving optoelectronic properties and stability of the perovskite thin films and devices. We believe that the full understanding on ILs would enhance the pace of perovskite photovoltaic technology transition.

\section{Results}

2.1. Photovoltaic Device and Performance. Achieving efficient PSCs is an important prerequisite for evaluating preparation methods and studying the mechanism of film formation. We first fabricated the devices with a structure of indium tin oxide (ITO)/tin oxide $\left(\mathrm{SnO}_{2}\right) / \mathrm{MAPbI}_{3} / 2,2^{\prime}, 7,7^{\prime}$-tetrakis $(N, N$ di-methoxyphenylamine)-9, $9^{\prime}$-spirobifluorene (Spiro-OMe$\mathrm{TAD}) / \mathrm{MoO}_{3} / \mathrm{Au}$. For the DMF solvent, high-quality film deposition processes require the use of antisolvent-assisted crystallization and need to be prepared in an inert atmosphere [12]. It should be noted that the thin films based on the MAAc solvent with large grains and low surface roughness (Figure S1) can be prepared in a natural environment with relative humidity of $20 \% \sim 80 \%$ by a one-step approach without the use of antisolvent treatment (Figure S2). As a result, PCEs of $20.49 \%$ and $21.18 \%$ were achieved in the best-performing DMF- and MAAc-based PSCs (Figure 1(a)), respectively. The detailed performance parameters are shown in Table 1. As far as we know, the PCE of MAAc PSCs is one of the highest reported efficiencies based on $\mathrm{MAPbI}_{3}$ PSCs (Table S1). The external quantum efficiency (EQE) and integrated $J_{\mathrm{SC}}$ are shown in Figure 1(b), where the integrated $J_{\mathrm{SC}}$ of $22.01 \%$ and $22.60 \mathrm{~mA} \mathrm{~cm}^{-2}$, respectively, agrees well with the measured $J_{\mathrm{SC}}$ from a current-voltage $(J-V)$ curve. Furthermore, MAAc devices show hysteresis-free $J-V$ curves under a forward and reverse scan (Figure 1(c), Table S2), which may be due to the bulk and surface defects being passivated, inhibiting ion migration $[10,11]$. As a result, the photocurrent density promptly achieves $22.49 \mathrm{~mA} \mathrm{~cm}^{-2}$ and a stabilized PCE of $21.14 \%$ at MPP $(0.94 \mathrm{~V})$ (Figure $1(\mathrm{~d})$ ). Furthermore, to further increase the PCE of the MAAc device, we doped $\mathrm{FABr}$ into $\mathrm{MAPbI}_{3}$. The PCE of $22 \%$ was achieved, which is the highest reported value in all one-step approaches in air (Figure 1(e), Table 1). Moreover, MAAc devices have high repeatability with the average efficiency of $20.58 \%\left(\mathrm{MAPbI}_{3}\right)$ and $21.33 \%$ (FABr-doped $\mathrm{MAPbI}_{3}$ ) (Figure 1(f)).

To further explore the effects of the two solvents on stability, the humidity, heat, and light stability of perovskite films and devices were measured. No change in XRD patterns was observed in MAAc perovskites, exposed in ambient air for even 2 years under humidity of 30\%-80\% (Figure S3). In addition, MAAc perovskite films can be maintained for $500 \mathrm{~h}$ and $800 \mathrm{~h}$ under $85^{\circ} \mathrm{C}$ and light conditions without the appearance of diffraction peaks of $\mathrm{PbI}_{2}$ (Figure $\mathrm{S} 4$ ). However, the DMF perovskite films suffer from serious degradation. Moreover, the maximum rate of MAAc perovskite powder decomposition is $351^{\circ} \mathrm{C}$ higher than that of DMF perovskite powder at $346^{\circ} \mathrm{C}$ with a thermal gravimetric analyzer (TGA) (Figure S5). Most importantly, the MAAc PSCs exhibited enhanced long-term stability, which retained more than $87 \%$ of their original PCE after 2000 hours in air (Figure S6), and the device after being placed in the air for $2500 \mathrm{~h}$ is shown in Figure S6, while the DMF devices maintain $30 \%$ of their original PCE merely after $1200 \mathrm{~h}$ and began to decay severely after $600 \mathrm{~h}$ (Figure S6), which may be attributed to the humidity effect with a large amount of generated $\mathrm{PbI}_{2}$, as demonstrated in Figure S4. Furthermore, the long-term stability of PSCs under continuous light stress for $1800 \mathrm{~h}$ was also studied (1 sun, in a glovebox filled with $\mathrm{N}_{2}$, Figure S7). The MAAc PSCs (more than 94\% of the original PCE) exhibit obviously enhanced stability compared to DMF PSCs (around $73 \%$ of the original PCE). It is worth noting that MAAc PSCs can maintain more than $82 \%$ of the original efficiency for $1000 \mathrm{~h}$ at high temperature $\left(85^{\circ} \mathrm{C}\right.$, in an $\mathrm{N}_{2}$ filled glovebox, Figure $1(\mathrm{~g}))$ and have better thermal stability than DMF PSCs (around 10\% of the original PCE for $800 \mathrm{~h}$ ). Operational stability is the closest requirement to commercial photovoltaic applications. The stability of 


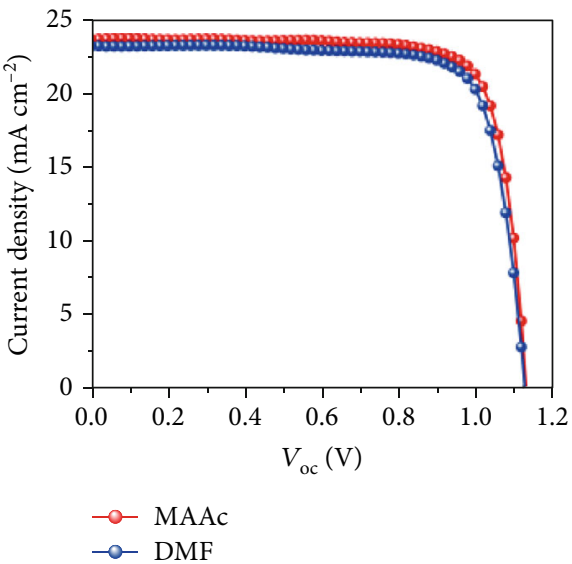

(a)

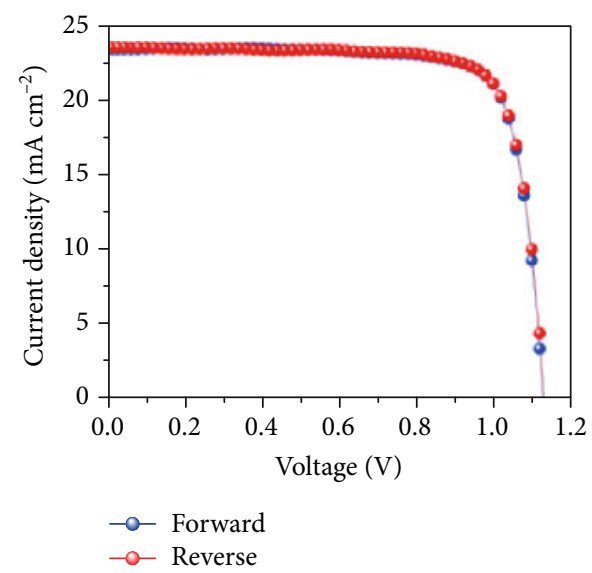

(c)

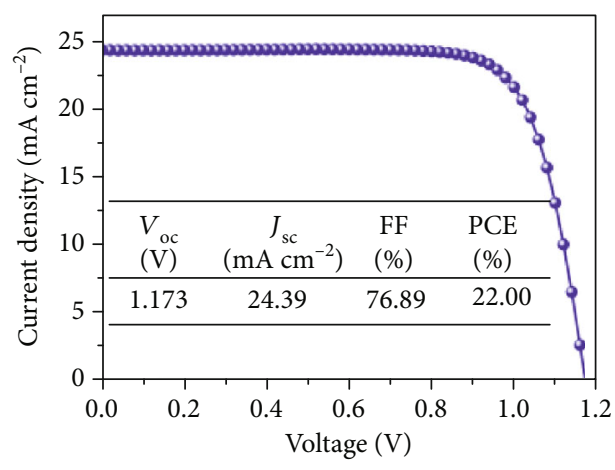

(e)

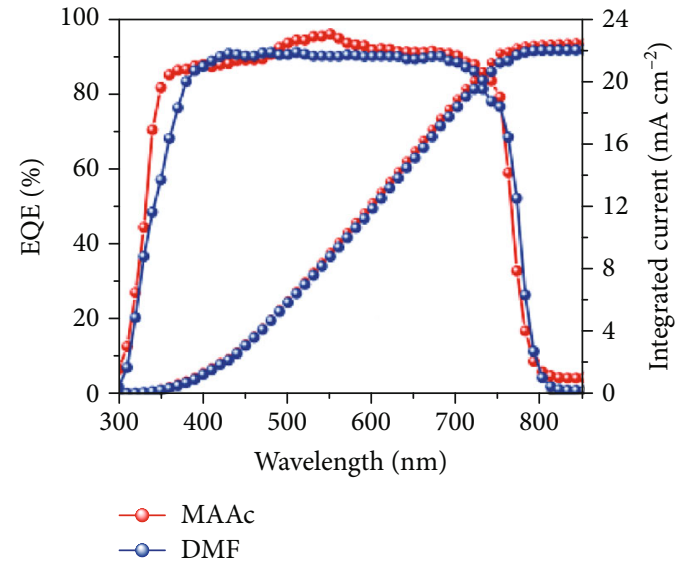

(b)

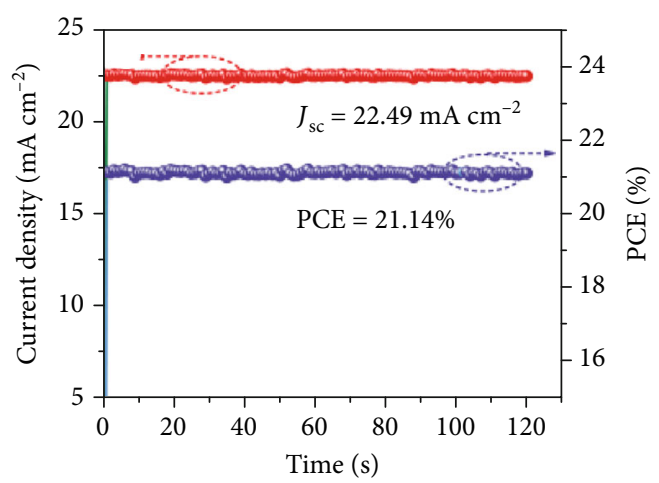

(d)

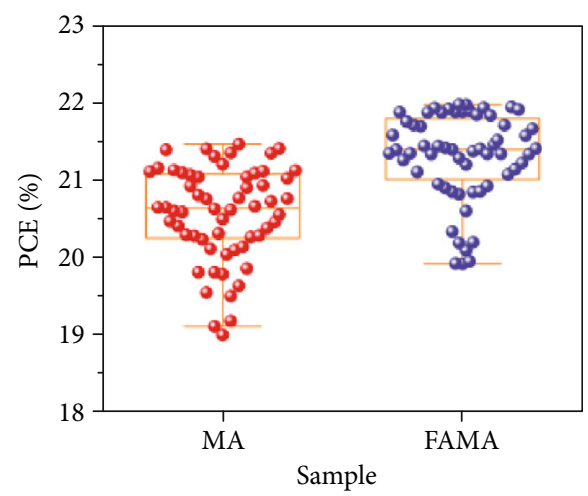

(f)

Figure 1: Continued. 


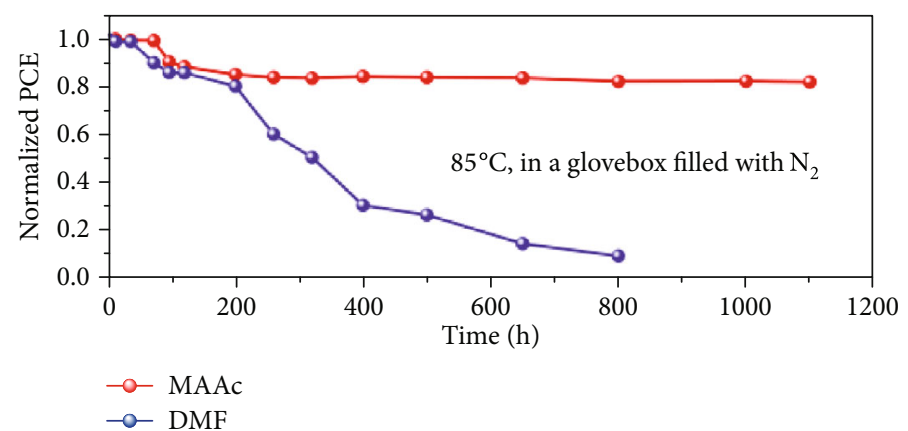

(g)

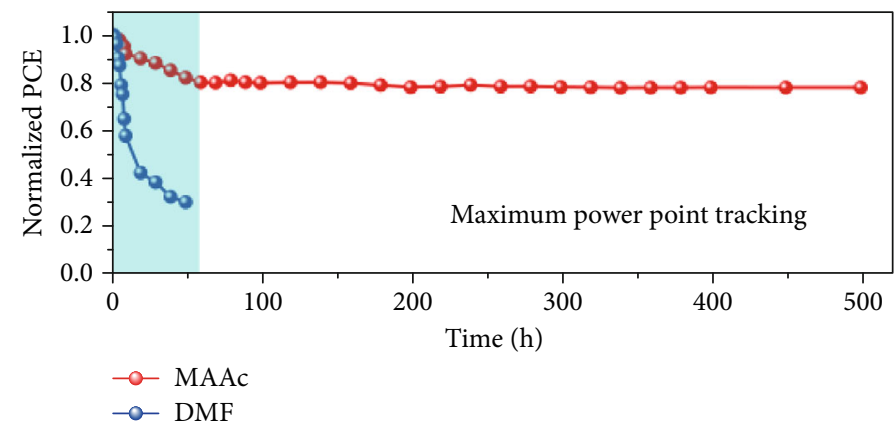

(h)

FIGURE 1: Photovoltaic performance and long-term stability of the PSCs. (a) The performance of the MAPbI ${ }_{3}$-based champion device. (b) EQE spectra and integrated $J_{\mathrm{SC}}$ of the $\mathrm{MAPbI}_{3}$-based champion device. (c) $J$ - $V$ curves under different scanning directions for MAAc PSCs. (d) The stabilized current density and power output of the $\mathrm{MAPbI}_{3}$ device for MAAc PSCs. (e) The performance of the champion device doped with FABr for MAAc PSCs. (f) The statistics of the PCEs of devices with and without FABr for MAAc PSCs. (g) Thermal stability of DMF and MAAc PSCs. The devices are maintained at $85^{\circ} \mathrm{C}$ condition in an $\mathrm{N}_{2}$-filled glovebox and measured regularly. (h) Operational stability of DMF and MAAc PSCs. MAAc and DMF PSCs are tracked at MPP $(0.94 \mathrm{~V}$ and $0.90 \mathrm{~V}$, respectively) under continuous 1-sun illumination in the glovebox.

TABLE 1: Summary of PSC parameters of different systems.

\begin{tabular}{lcccc}
\hline Solvents & $V_{\mathrm{OC}}(\mathrm{V})$ & $J_{\mathrm{SC}}\left(\mathrm{mA} \mathrm{cm}^{-2}\right)$ & FF $(\%)$ & PCE $(\%)$ \\
\hline DMF (MA) & $1.129(1.107 \pm 0.02)$ & $22.97(22.87 \pm 0.13)$ & $78.67(76.94 \pm 1.68)$ & $20.49(19.48 \pm 0.98)$ \\
MAAc (MA) & $1.132(1.117 \pm 0.02)$ & $23.39(23.33 \pm 0.07)$ & $80.01(78.96 \pm 1.03)$ & $21.18(20.58 \pm 0.61)$ \\
MAAc (MA/FA) & $1.173(1.164 \pm 0.01)$ & $24.39(24.28 \pm 0.35)$ & $76.87(75.47 \pm 1.21)$ & $22.00(21.33 \pm 0.57)$ \\
\hline
\end{tabular}

the device was traced for $500 \mathrm{~h}$ under MPP $(0.94 \mathrm{~V})$ (Figure $1(\mathrm{~h})$ ). The MAAc perovskite device rapidly decayed to the original $80 \%$ within $50 \mathrm{~h}$ and remained stable. However, the DMF device has been completely attenuated after 50 hours of continuous operation $(0.90 \mathrm{~V})$, showing extremely unstable performance.

The difference in efficiency and especially in stability of MAAc PSCs over DMF PSCs inspired us to reveal the origination. In the perovskite solution process, the solvent will participate in the entire process from solution to film. To comprehensively and deeply understand the influence of solvents on this process and the device, we conducted a detailed study from the precursor solution, the film formation process, the crystal structure, and the carrier transport characteristics of the device.

2.2. Chemical Interaction between the Solvent and Solute (Solvent). Compared with traditional solvents, ILs have been widely used as solvents in industrial production because of their stable physical and chemical properties, negligible vapor pressure, and harmless properties [19]. Here, a series of novel amine carboxylic acid ILs, e.g., methylammonium formate (MAFa), methylammonium acetate (MAAc), methylammonium propionate $(\mathrm{MAPa})$, ethylammonium acetate (EAAc), propylammonium acetate (PAAc), and butylammonium acetate (BAAc), were synthesized as solvents and used to prepare perovskite precursor solution. As shown in Figure 2(a), a hybrid perovskite $\mathrm{MAPbI}_{3}$ precursor $(300 \mathrm{mM} / \mathrm{ml})$ can be totally dissolved with colorless solutions. Moreover, different perovskite precursors containing MA-, FA-, and Cs-based perovskites can be effectively dissolved in the MAAc solvent as an example (Figure 2(b)), which strongly suggests a class of universal solvent for halide perovskites. Up to now, high-efficiency PSCs are prepared by perovskite precursor solution with mixed solvents, e.g., DMF and DMSO. Due to the differences in the physical and 


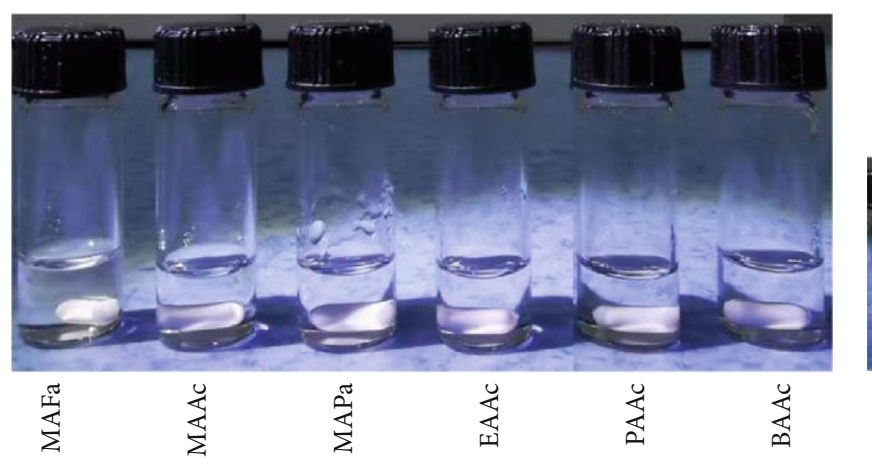

(a)

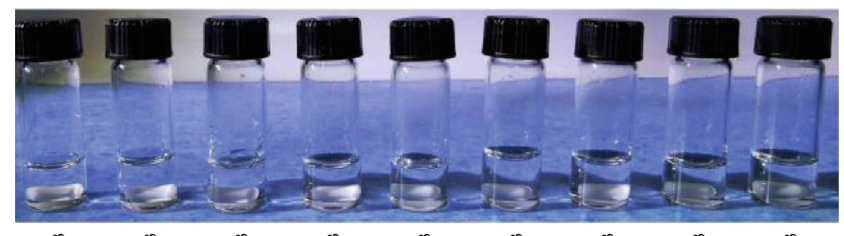

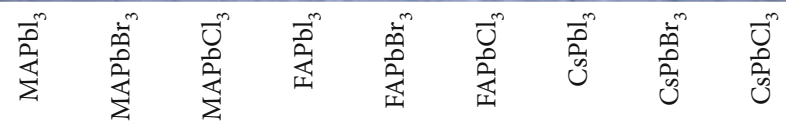

(b)

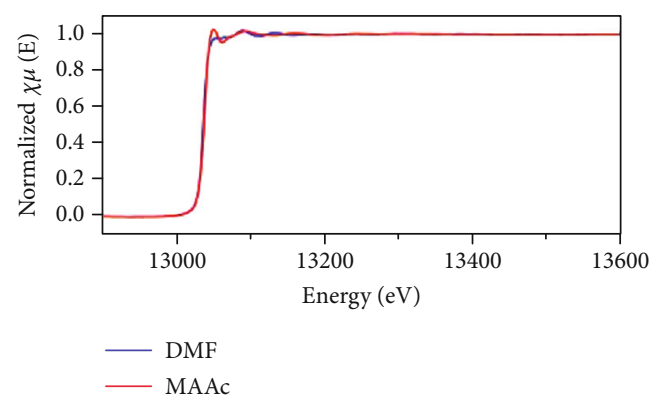

(c)

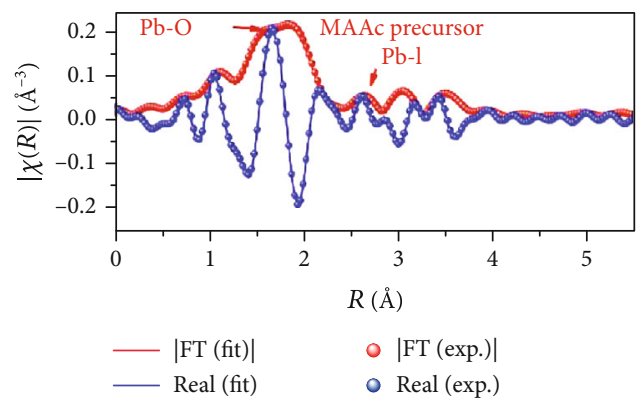

(d)

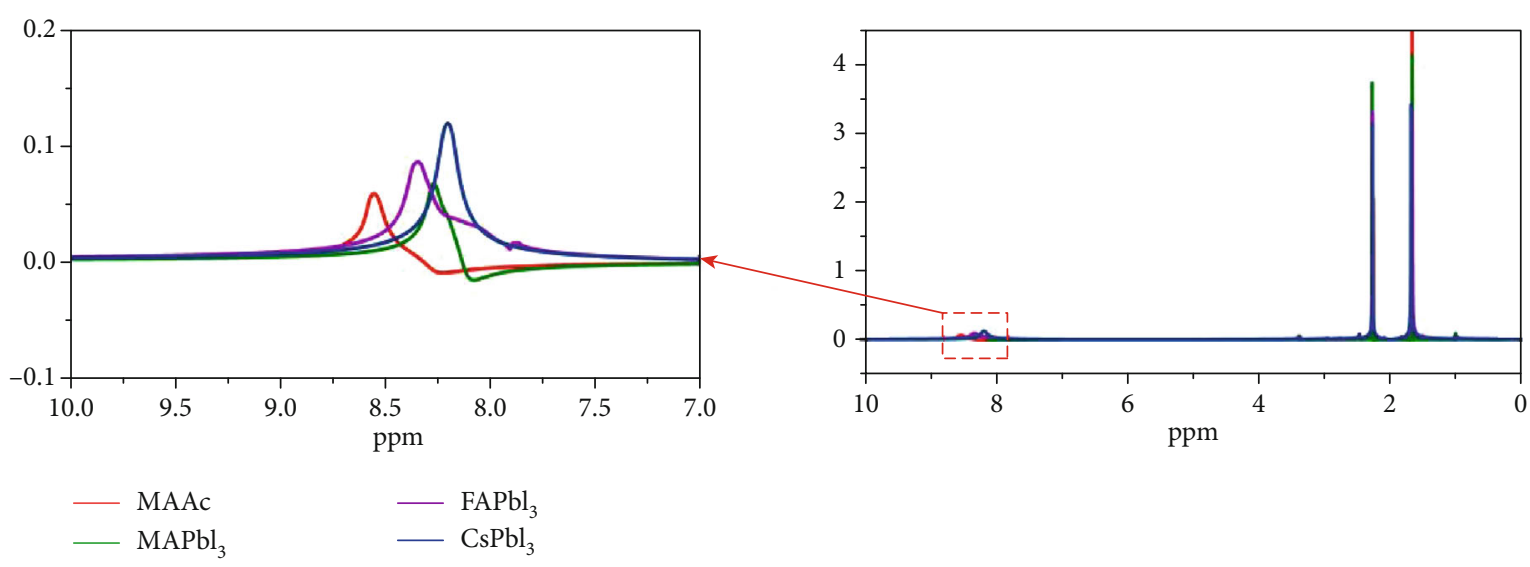

(f)

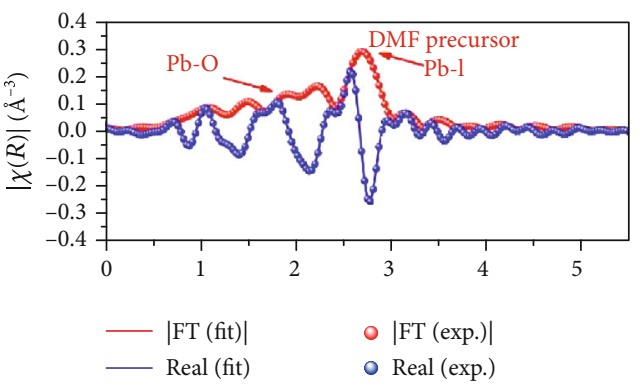

(e)

2: Perovskite precursor solution chemistry. (a) The solution images of the MAPbI ${ }_{3}$ perovskite precursor dissolved in different IL solvents. (b) The solution images of different perovskite precursors (MA-, FA-, and Cs-based perovskites) dissolved in the MAAc solvent. (c) The $\mathrm{Pb}$ L3-edge XANES spectra of the DMF and MAAc perovskite precursors. The $k^{2}$-weighted Fourier transforms of the EXAFS spectra at the $\mathrm{Pb} \mathrm{L3}$-edge for the (d) MAAc and (e) DMF perovskite precursors. (f) ${ }^{1} \mathrm{H}$ NMR spectra of a pure MAAc solvent and different perovskite precursors in the MAAc solvent. 
chemical properties of the solvents, however, a large number of defects are probably generated during the film formation process, which results in adverse impact on device performance. Amine carboxylic acid salt ILs as single solvents can effectively avoid the negative effects of solvent competition, which facilitates the preparation of high-quality films and high-efficiency PSCs.

The colorless characteristics indicate the similar interaction appearance in the amine carboxylic acid IL solutions. For better understanding the interaction between ILs and perovskite precursors, we take MAAc as an example to discuss. We first studied the chemical bonding environment of $\mathrm{Pb}$ atoms based on DMF and MAAc solvents by the X-ray absorption near-edge structure (XANES). The MAAc precursor solution XANES data exhibit a strong shoulder peak at approximately $13050 \mathrm{eV}$ than those from the DMF precursor solution (Figure 2(c)), which was attributed to the presence of $\mathrm{Pb}-\mathrm{O}$ coordination from the coordination complex of $\mathrm{PbI}_{2}-\mathrm{MAAc}$, as in previous reports $[7,28,29]$. We therefore further performed a linear combination fit for the realspace extended X-ray absorption fine structure (EXAFS) spectra of MAAc and DMF precursor solutions, as shown in Figures 2(d) and 2(e). A strong $\mathrm{Pb}-\mathrm{O}$ coordination peak was observed at near $1.65 \AA$ in the MAAc precursor solution, and a small amount of $\mathrm{Pb}-\mathrm{I}$ coordination is present at near $2.6 \AA$ A. In contrast, DMF precursor solution exhibited a strong $\mathrm{Pb}-\mathrm{I}$ coordination peak with a small amount of $\mathrm{Pb}-\mathrm{O}$ coordination, which indicates that the perovskite precursor in the DMF solvent is dominated by iodine complexes due to the greater coordination capacity of $\mathrm{I}^{-}$than $\mathrm{DMF}$, as in previous reports [29, 30]. Moreover, as shown in Figure 2(f), the ${ }^{1} \mathrm{H}$ NMR spectra of the three perovskite precursor solutions $\left(\mathrm{MAPbI}_{3}, \mathrm{FAPbI}_{3}\right.$, and $\mathrm{CsPbI}$ ) showed the clear blue shift of the $\mathrm{N}-\mathrm{H}$ peak with respect to the pure MAAc solvent (shown in an internal enlarged view in Figure 2(f)), which proved the formation of hydrogen bonding of $\mathrm{N}-\mathrm{H} \cdots \mathrm{I}$ between MAAc and $\mathrm{PbI}_{2}$ and/or MAI (CsI). Therefore, it is now clear that MAAc dissolves the perovskite precursors by forming $\mathrm{Pb}-\mathrm{O}$ coordination and $\mathrm{N}-\mathrm{H} \cdots \mathrm{I}$ hydrogen bonds, which is different from the traditional iodoplumbate complexes [18]. The complicated chemical bond system consisting of strong chelation and hydrogen bonding interaction provides a necessary encapsulation of the perovskite precursor, leading to the colorless solution and making the precursor solution stable. Based on the unique dissolution characteristics of MAAc over traditional solvents, e.g., DMF and DMSO, the saturation concentration of the perovskite precursor solution can reach $4 \mathrm{M}$, which far exceeds those of DMF (1.5 M), DMSO (1.9 M), and GBL (2.2 M) [31]. Higher saturation concentration has the benefit to allow the fabrication of thick perovskite films, which has been demonstrated to significantly improve the stability of PSCs [32].

\subsection{Perovskite Crystallization and Structure Transformation} (Additive). Solvents can affect the chemical properties of the precursor solution and determine the crystallization of perovskite. To understand the effect of the MAAc solvent on perovskite crystallization, we first investigate the entire crystal growth dynamic process by in situ real-time grazing incidence wide-angle X-ray scattering (GIWAXS), as compared to that in the traditional DMF solvent (the scheme diagram of the GIWAXS setup is shown in Figure S8). Note that the MAAc perovskite precursor solution is firstly spin coated onto an $\mathrm{ITO} / \mathrm{SnO}_{2}$ substrate at room temperature. A transparent oily-like noncrystalline thin film is obtained (Figure S9), which indicates a highly concentrated perovskite precursor. Then, the films are continuously annealed at $100^{\circ} \mathrm{C}$ in ambient air and radiated by X-ray at the same time. The false color intensity maps in Figures 3(a) and 3(d) show the evolution of the perovskite crystal structure over time based on MAAc and DMF solvents, respectively. We found that the (110) crystal plane $\left(q_{x y}=10 \mathrm{~nm}^{-1}\right)$ of the MAAc perovskite film reaches the strongest crystalline state much faster than that of the DMF perovskite film. The position of the (110) crystal plane in the MAAc perovskite film takes only $70 \mathrm{~s}$ to fully convert to $q_{x y}=10 \mathrm{~nm}^{-1}$, while the DMF perovskite film needs $130 \mathrm{~s}$ (Figure S10), which corresponds to the rapid crystallization phenomena of the MAAc perovskite film in Figure 3(a). Moreover, the MAAc perovskite film exhibited a larger peak area and narrower diffraction full width at half maximum (FWHM) of the (110) crystal plane than the DMF perovskite film (Figure S11). It should be noted that no changes on the peak area and FWHM of the MAAc perovskite film over time were observed (Figures S11 and S12), corresponding to the steady crystalline state of the MAAc perovskite film over that of the DMF perovskite film in Figure 3(a). From the intensity distribution curve of in situ 1D GIWAXS integral (Figure 3(b)), nonperovskite diffraction peaks were observed at M-1 $\left(q_{x y}=3.8 \mathrm{~nm}^{-1}\right)$, M-2 $\left(q_{x y}=6.8 \mathrm{~nm}^{-1}\right)$, and M-3 $\left(q_{x y}=7.6 \mathrm{~nm}^{-1}\right)$ in the MAAc perovskite film at the beginning of annealing. They are weaker with respect to the perovskite phase $\left(q_{x y}=10 \mathrm{~nm}^{-1}\right)$, and the diffraction intensity rapidly weakens or even disappears with increasing annealing time. This is because the precursor has formed a dispersed uniform cluster in the MAAc system due to the strong component interaction, which inhibits the formation of the nonperovskite phase and promotes the quick transformation of the stable perovskite phase. However, a large number of nonperovskite phases were observed for the DMF perovskite film located at $q_{x y}=3.8 \mathrm{n}$ $\mathrm{m}^{-1}$ (D-1), $q_{x y}=4.7 \mathrm{~nm}^{-1}$ (D-2), $q_{x y}=6.9 \mathrm{~nm}^{-1}$ (D-3), and $q_{x y}=8.0 \mathrm{~nm}^{-1}$ (D-4), which did even not disappear with the growth of perovskite crystals (Figure 3(e)).

To further study the crystal growth and orientation, we extracted 2D GIWAXS diffraction images of the final perovskite films. A series of similar bright diffraction patterns were obtained at $q_{x y}=10,20$, and $22.4 \mathrm{~nm}^{-1}$, corresponding to the (110), (220), and (310) crystal planes, respectively (Figures 3(c) and 3(f)). It can be seen that the DMF thin film exhibits multiple diffraction rings (Figure 3(f)), indicating that the crystals are randomly arranged, which may result in a large number of defects [33]. In contrast, discrete Bragg spots can be clearly observed on the diffraction ring of each crystal plane in the MAAc perovskite film (Figure 3(c)), which indicates that the perovskite crystals are ordered in 


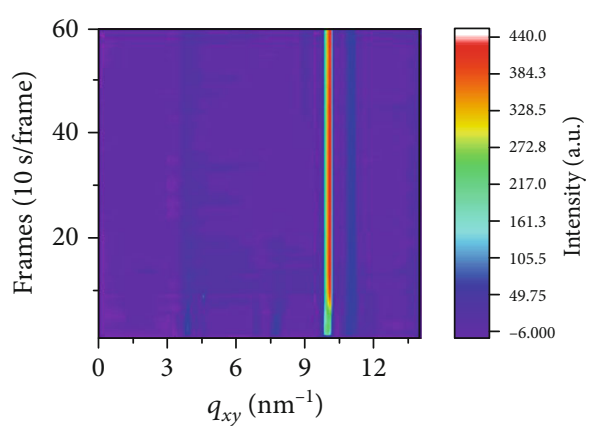

(a)

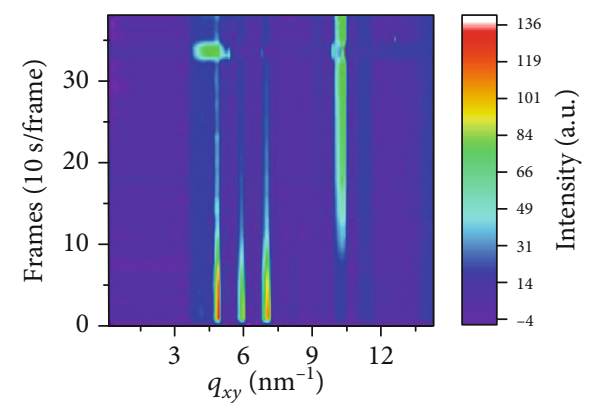

(d)

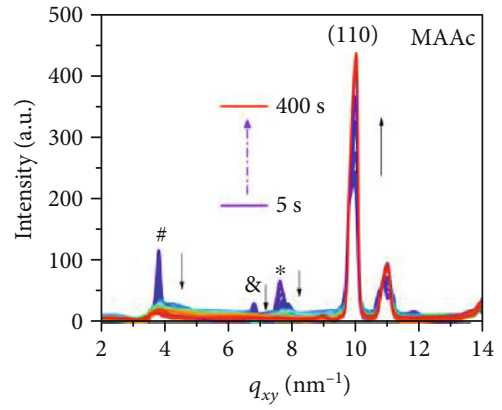

\# M-1

\& $\mathrm{M}-2$

* M-3

(b)

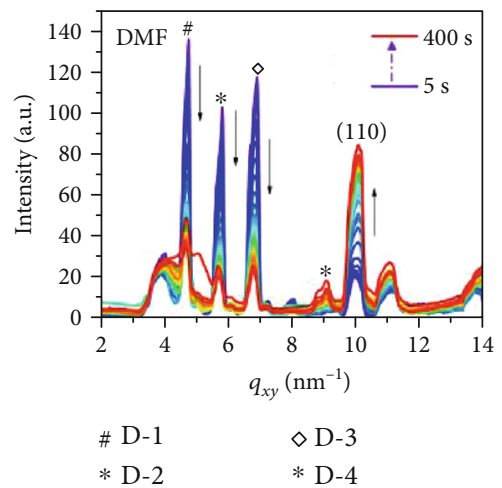

(e)

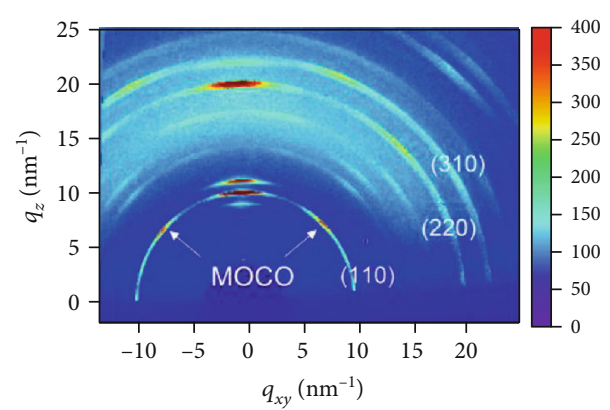

(c)

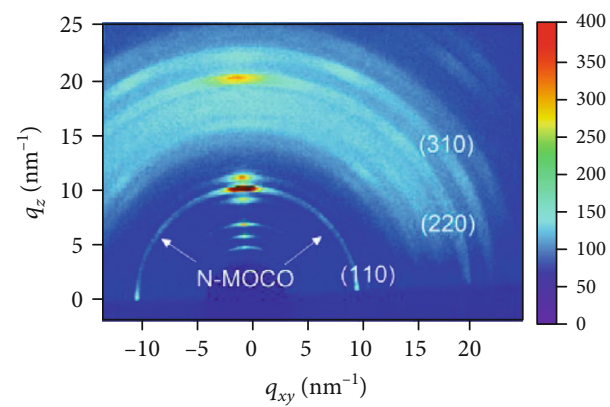

(f)
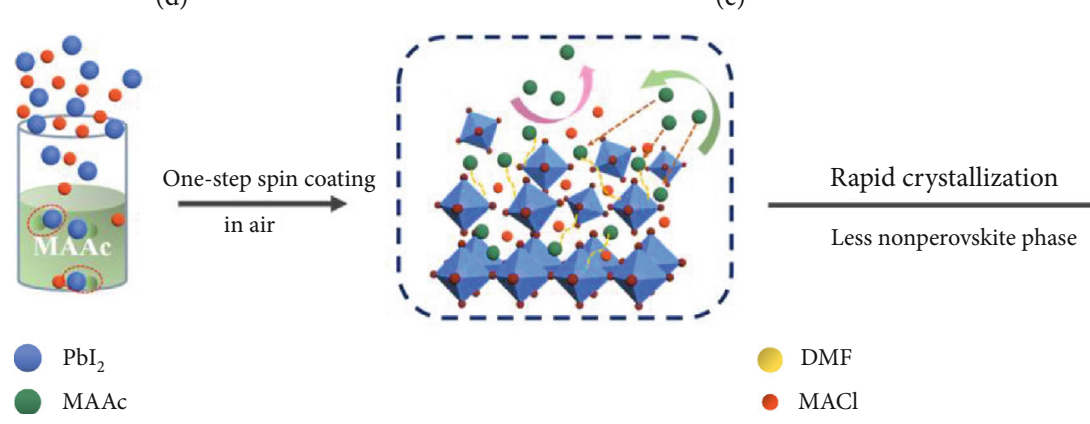

Less nonperovskite phase

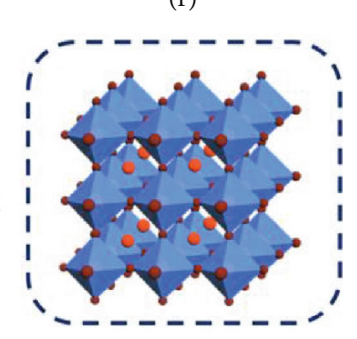

(1) DMF

- MACl

(g)
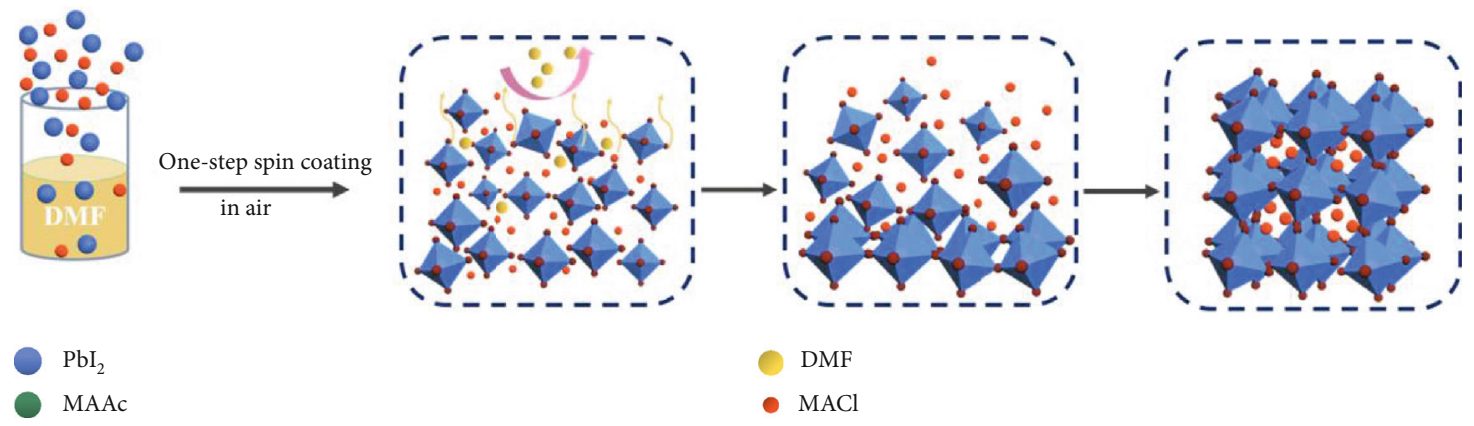

DMF

- $\mathrm{MACl}$

(h)

FIGURE 3: The crystallization and structure transformation by the time-resolved GIWAXS. (a) 2D mapping of a real-time evolution process based on MAAc perovskites. (b) 1D GIWAXS diffraction pattern of MAAc thin films in the $q_{x y}$ direction for 40 frames ( $10 \mathrm{~s}$ per frame). (c) $2 \mathrm{D}$ GIWAXS diffraction images of MAAc perovskites. (d) 2D mapping of a real-time evolution process based on DMF perovskite. (e) 1D GIWAXS diffraction pattern of DMF thin films in the $q_{x y}$ direction for 40 frames (10 s per frame). (f) 2D GIWAXS diffraction images of MAAc perovskites. The diagram of the mechanism of the perovskite crystal growth process in different solvents: (g) MAAc and (h) DMF. 
multiple directions and have a better preferred out-of-plane orientation [34]. In order to further quantitatively analyze the multiple and ordered crystal orientations (MOCO) of perovskite grains, we obtained the corresponding azimuthal distribution map by radial integration of the (110) diffraction rings of the two films (Figure S13). The MAAc perovskite film exhibits a narrower sharp peak at the azimuth angle of $90^{\circ}$, indicating that the perovskite film has a higher degree of orientation. Meantime, the azimuth angles of $21.8^{\circ}\left(180^{\circ}-21.8^{\circ}\right)$ and $45.0^{\circ}\left(180^{\circ}-45.0^{\circ}\right)$ were also observed in the MAAc perovskite film, which also represents the preferential orientations of the crystal. In addition, the azimuthal distribution of time evolution also proves that MAAc can quickly crystallize and stabilize rapidly (Figure S14). These results demonstrate that MAAc can promote the ordered and highly oriented growth of perovskite in multiple directions, which greatly enhances the extraction and transport of carriers of perovskites, thereby improving the device performance of the PSCs [34].

These results show that MAAc is not only a good solvent but also an effective additive for perovskite crystallization. Figures 3(g) and 3(h) present the schematic of the evolution process of perovskite films from precursor solution to highquality crystals. For precursor solution, as shown by equation (1), when the $\mathrm{PbI}_{2}$ and $\mathrm{MAl}$ were dissolved in $\mathrm{MAAc}, \mathrm{Pb}^{2+}$ will combine with $\mathrm{CH}_{3} \mathrm{COO}^{-}\left(\mathrm{Ac}^{-}\right)$to form a weak electrolyte $\mathrm{Pb}(\mathrm{Ac})_{2}$. Furthermore, $\mathrm{Pb}^{2+}$ will also combine with the surrounding MAI to form agglomerates with less binding energy. The thermodynamic instability of $\mathrm{Pb}(\mathrm{Ac})_{2}$ causes the precursor to evaporate $\mathrm{CH}_{3} \mathrm{COOH}(\mathrm{HAc})$ and $\mathrm{CH}_{3} \mathrm{NH}_{2}$ (MA) gases upon heat treatment, prompting the further rightward reaction of the following equation (2).

$$
\begin{gathered}
\mathrm{PbI}_{2}+\mathrm{CH}_{3} \mathrm{NH}_{3} \mathrm{I}+\mathrm{CH}_{3} \mathrm{COONH}_{3} \mathrm{CH}_{3} \\
\longrightarrow \mathrm{Pb}\left(\mathrm{CH}_{3} \mathrm{COO}\right)_{2} \cdots \mathrm{CH}_{3} \mathrm{NH}_{3} \mathrm{I} \\
\mathrm{Pb}\left(\mathrm{CH}_{3} \mathrm{COO}\right)_{2} \cdots \mathrm{CH}_{3} \mathrm{NH}_{3} \mathrm{I} \longrightarrow \mathrm{CH}_{3} \mathrm{NH}_{3} \mathrm{PbI}_{3} \\
+\mathrm{CH}_{3} \mathrm{COOH} \uparrow+\mathrm{CH}_{3} \mathrm{NH}_{2} \uparrow
\end{gathered}
$$

Compared to DMF, MAAc as a solvent provides the above reaction process inside the precursor solution, avoiding the formation of multiple intermediate phases during the perovskite film crystallization process, which directly blocks the channel of defect generated. Notably, the agglomerates in equation (2) may be thermodynamically unstable coordination complexes between $\mathrm{CH}_{3} \mathrm{COO}^{-}, \mathrm{Pb}^{2+}$, and $\mathrm{MA}^{+}$, which may explain the change of peak position at the beginning of the annealing in Supplementary Fig. 10. Due to the fact that $\mathrm{Pb}^{2+}$ is combined with $\mathrm{Ac}^{-}$in the form of a covalent bond, it will evaporate in the fixed direction of the covalent bond force rather than in all directions under the heat treatment. At the same time, $\mathrm{I}^{-}$could quickly migrate to the crystal lattice to replace $\mathrm{Ac}^{-}$. As a result, the perovskite grows orderly along the direction of the force (Figure $3(\mathrm{~g})$ ). However, for the traditional solvent DMF, the crystallization process must first evaporate the solvent; then, the crystals are randomly arranged, and finally a perovskite structure can be achieved (Figure 3(h)).

2.4. In Situ Chemically Anchored Grain Boundaries (Passivation). The features of high boiling point and low vapor pressure of MAAc determine that it may not be completely evaporated in the final perovskite film. As shown in Figure $\mathrm{S} 15$, the $\mathrm{C}=\mathrm{O}\left(1600.68 \mathrm{~cm}^{-1}\right)$ stretching vibration from $\mathrm{Ac}^{-}$can still be clearly observed in the MAAc perovskite powder, which confirms the residue of MAAc in the final perovskite film. Considering the above GIWAXS patterns, we have not found an obvious shift in the diffraction angle in the DMF and MAAc perovskite films, which suggests that residual MAAc does not enter the lattice. Therefore, we speculate that MAAc may exist at the grain boundaries (GBs) of the perovskite films. To confirm our assumption, we used high-resolution transmission electron microscopy (HR-TEM) to examine the detailed structure information of grains and GBs in the DMF and MAAc perovskites. The clear amorphous GB walls were observed in the MAAc perovskite film (Figure 4(a)), while no obvious amorphous region was observed at GBs in the DMF perovskite film (Figure 4(b)), which confirms the presence of MAAc at GBs $[28,35]$. Moreover, the red frame region was magnified and analyzed using fast Fourier transform (FFT), in which an interplanar spacing of $6.3 \AA$ completely coincides with the (110) planes of $\mathrm{MAPbI}_{3}$ [36]. We found the same lattice fringes and FFT image in the DMF perovskite film, demonstrating the same perovskite structure in both films, corresponding to the GIWAXS patterns. To assess the passivation effect, the local conductivity of the MAAc and DMF perovskite films was measured by conductive atomic force microscopy (c-AFM) under a bias voltage of $2 \mathrm{~V}$ (Figures $4(\mathrm{c})$ and $4(\mathrm{~d})$ ). The brighter contrast of the MAAc and DMF film current images (average photocurrent $1.27 \mathrm{nA}$ vs. $0.45 \mathrm{nA}$ ) indicated more conducting current flow through the MAAc perovskite film, which suggests that the MAAc perovskite film is beneficial to carrier separation and improves the photovoltaic performance [37]. Moreover, GBs of the MAAc perovskite film show brighter contrast, indicating that the GBs can efficiently flow the current in the MAAc perovskite film. In contrast, the obvious current contrast was not observed between grains and GBs in the DMF perovskite film, and we only can see uneven and discontinuous bright spots. This strongly demonstrated that the GBs for the MAAc perovskite film can clearly be considered charge transporting channels and further confirm the passivation effect of MAAc in the perovskite film $[7,28]$.

We further explored the passivation mechanism of MAAc at the GBs. We dissolved $\mathrm{PbI}_{2}$ into the MAAc solvent and investigated the characteristics of powders obtained from the $\mathrm{PbI}_{2}-\mathrm{MAAc}$ films. As shown in Figure $\mathrm{S} 15$, the $\mathrm{C}=\mathrm{O}$ vibration peak $\left(1604.51 \mathrm{~cm}^{-1}\right)$ in the $\mathrm{PbI}_{2}-\mathrm{MAAc}$ powder shifted to a low wavenumber as compared to $\mathrm{C}=\mathrm{O}$ $\left(1645.23 \mathrm{~cm}^{-1}\right)$ in the pure MAAc, which is attributed to the coordination interaction between $\mathrm{C}=\mathrm{O}$ of MAAc and undercoordinated $\mathrm{Pb}^{2+}\left(\mathrm{I}^{-}\right.$vacancy) in the $\mathrm{PbI}_{2}-\mathrm{MAAc}$ films [38]. Moreover, we found that the position of $\mathrm{Pb}^{2+}\left(4 \mathrm{f}_{5 / 2}\right.$, 

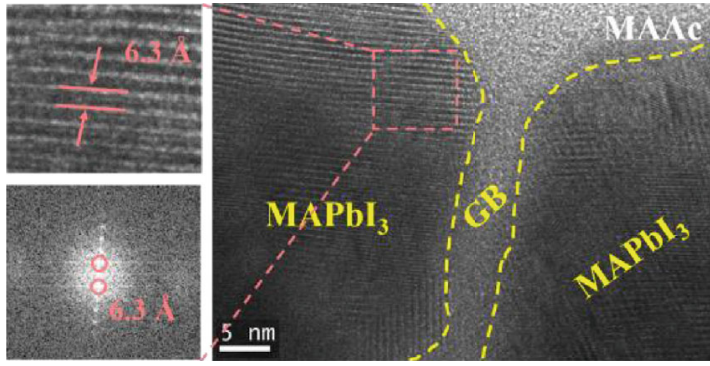

(a)
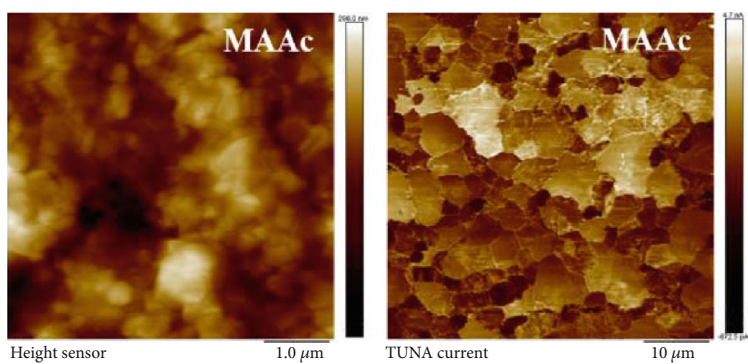

(c)
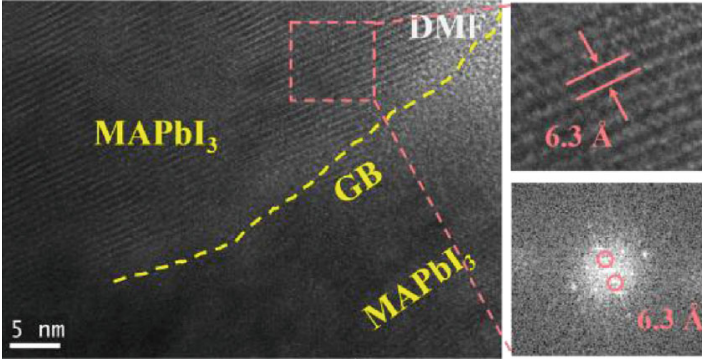

(b)
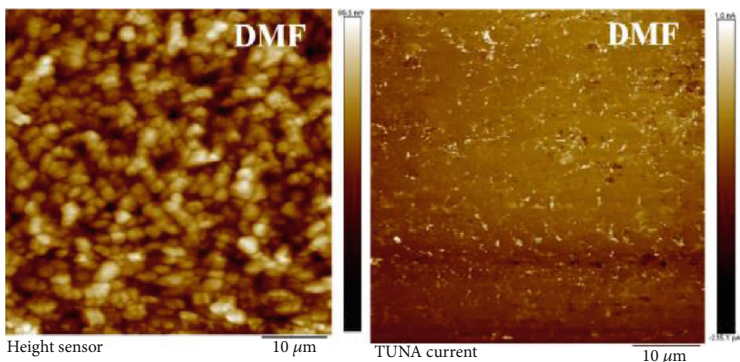

(d)

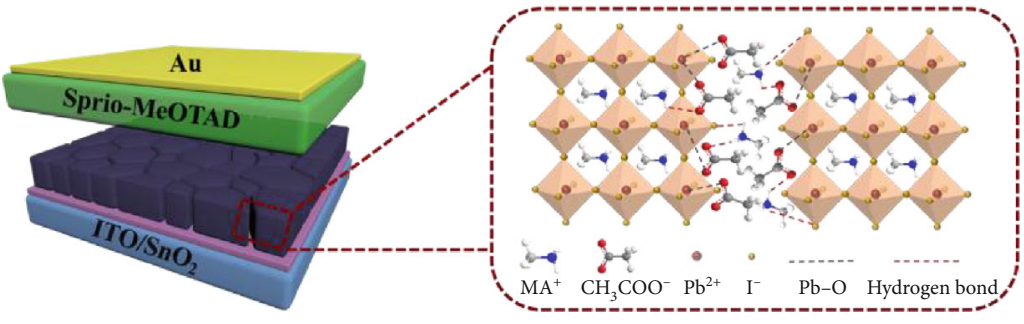

(e)

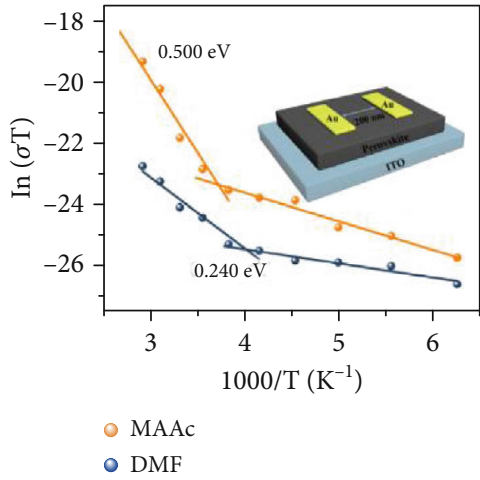

(f)

FIgURE 4: Microstructure characterization of perovskites. High-resolution transmission electron microscopy (HR-TEM) images of (a) MAAc perovskite (left: the magnified lattice fringes and FFT about the red frame region) and (b) DMF perovskite (right: the magnified lattice fringes and FFT about the red frame region). Conductive atomic force microscopy (c-AFM) and topological images of (c) MAAc perovskite and (d) DMF perovskite. (e) The structure diagram of grains and GBs in the MAAc perovskite. (f) The temperature-dependent conductivity of MAAc and DMF perovskite films for the activation energy $\left(E_{\mathrm{a}}\right)$ of ion migration.

$4 \mathrm{f}_{7 / 2}$ ) in the $\mathrm{PbI}_{2}$-MAAc film has tendency towards lower binding energy relative to the $\mathrm{PbI}_{2}-\mathrm{DMF}$ film in the $\mathrm{X}$-ray photoelectron spectroscopy (XPS) spectra (Figure S16). The peak of the $\mathrm{Pb}-\mathrm{O}$ bond can further be observed in Raman spectrum of the $\mathrm{PbI}_{2}-\mathrm{MAAc}$ film (Figure S17). These results confirm the strong interaction between undercoordinated $\mathrm{Pb}^{2+}$ and $\mathrm{O}$ atom in $\mathrm{Ac}^{-}$, which are consistent with previous reports that the Lewis base site $\mathrm{C}=\mathrm{O}$ group can provide an electron pair to the undercoordinated $\mathrm{Pb}^{2+}$ in the perovskite, thereby effectively passivating the perovskite film $[7,38]$. Together with the hydrogen bonds, therefore, the diagram of grains and GBs of MAAc perovskites can be drawn in Figure 4(e), in which the MAAc at GBs stabilized by intrinsic hydrogen bonding between $\mathrm{MA}^{+}$and $\mathrm{Ac}^{-}$can anchor perovskite octahedron through $\mathrm{Pb}-\mathrm{O}$ (undercoordinated $\mathrm{Pb}^{2+}$ of $\mathrm{MAPbI}_{3}$ and $\mathrm{C}=\mathrm{O}$ of MAAc), N-H $\cdots \mathrm{I}\left(\mathrm{MA}^{+}\right.$of MAAc and $\mathrm{I}^{-}$of $\left.\mathrm{MAPbI}_{3}\right)$, and $\mathrm{N}-\mathrm{H} \cdots \mathrm{O}\left(\mathrm{MA}^{+}\right.$of $\mathrm{MAPbI}_{3}$ and
C-O of MAAc), which can effectively stabilize the structure of perovskite and inhibit defects $[7,28]$.

To examine the effect of passivation of MAAc, we explored the trap density, ion migration, and carrier transport kinetics in the final MAAc perovskite films in comparison to the DMF perovskite films. For trap density, the bulk trap density of the DMF perovskite film is calculated to be $5.17 \times 10^{16} \mathrm{~cm}^{-3}$ by femtosecond transient absorption (fsTA) spectra, respectively (Figure S18). In sharp contrast, the bulk trap density of the MAAc perovskite film is an order of magnitude lower than that of the DMF perovskite film, which is only $3.90 \times 10^{15} \mathrm{~cm}^{-3}$ (Figure S18). The lower defect state density of the MAAc perovskite was further confirmed by capacitance-voltage $(C-V)$ measurement $\left(3.16 \times 10^{15} \mathrm{~cm}^{-3}\right)$ (Figure S19). Furthermore, the dark current density of the MAAc device is obviously lower than that of the DMF device, indicating that MAAc perovskite 
could facilitate the charge transport and reduce the charge recombination (Figure S20) [23]. Compared to the DMF devices, the MAAc device has a smaller capacitance in the low-frequency region compared to the DMF device, which again proves that the MAAc device has fewer defects and less recombination (Figure S21) [23].

For ion migration, the lateral device structure is used to measure ion migration activation energy $\left(E_{\mathrm{a}}\right)$ of ion conduction (Figure 4(f)), which represents the ease of ion migration, and can be obtained from the temperature dependence of the conductivity in the perovskite film [28]. The ion migration rate in perovskite is calculated by $E_{\mathrm{a}}$ according to the Nernst-Einstein equation:

$$
\sigma(T)=\frac{\sigma_{0}}{T} \exp \left(\frac{E_{\mathrm{a}}}{k T}\right)
$$

where $k$ represents the Boltzmann constant and $\sigma_{0}$ is a constant. $E_{\mathrm{a}}$ is obtained from the slope of $\ln (\sigma T)-(1 / k T)$ [39]. As shown in Figure 4(f), ions start to migrate at $268 \mathrm{~K}$ in the MAAc perovskite film, while the threshold temperature drops to $248 \mathrm{~K}$ in the DMF perovskite film. Meanwhile, $E_{\mathrm{a}}$ in the MAAc perovskite film is significantly increased from $0.24 \mathrm{eV}$ (DMF perovskite film) to $0.48 \mathrm{eV}$, which indicates that ion migration is effectively suppressed in the MAAc perovskite films compared to the DMF perovskite films. The reduction of defects and the suppression of ion migration are attributed to the passivation of GBs by residual MAAc in the film. Perovskite crystals with low defects and suppressed ion migration are beneficial for long-term stability of films and devices [40-42].

For carrier transport kinetics, we monitored the kinetic traces at a band edge (PB2) of the MAAc and DMF perovskite films by the TA spectra (Figures S22a and S22d). The DMF perovskite film has an average lifetime of only $8.1 \mathrm{~ns}$, while the MAAc perovskite film has a prolonged average lifetime of $78.6 \mathrm{~ns}$ due to the lower trap density (Figures S23a and S23b). In regard to the carrier lifetimes at the band edge of perovskite, they were substantially shortened when the perovskites were interfaced with $\mathrm{SnO}_{2}$ (Figures $\mathrm{S} 22 \mathrm{~b}$ and S22e) and Spiro-OMeTAD layers (Figures S22c and S22f), with fitted lifetimes of 23.2 and $8.5 \mathrm{~ns}$ for the MAAc perovskite film (Figure S23a), as compared to $3.2 \mathrm{~ns}$ and $3.7 \mathrm{~ns}$ for the DMF perovskite film, respectively (Figure S23b). The charge carrier transfer efficiency can be estimated to be $70 \%$ for MAAc perovskite/Spiro-OMeTAD and $90 \%$ for $\mathrm{SnO}_{2}$ /MAAc perovskite, while DMF perovskites gave those even as low as $54 \%$ and $60 \%$ (Tables S3 and S4). In addition, the electron and hole diffusion lengths $\left(L_{\mathrm{D}}\right)$ perpendicular to the film surface were calculated using the diffusion model. The MAAc perovskite gave longer electron and hole $L_{\mathrm{D}}$ of $138 \mathrm{~nm}$ and $257 \mathrm{~nm}$, respectively, than those of $111 \mathrm{~nm}$ and $98 \mathrm{~nm}$, respectively, for the DMF perovskite.

\section{Discussion}

In summary, we have revealed the origin of high efficiency and long-term stability in protic amine carboxylic acid ILbased perovskite photovoltaic. We concluded that ILs have the "three-in-one" functions of solvents, additive, and passivation for facial fabrication of efficient and stable PSCs. The unique chemical bonding properties of ILs by chelation and hydrogen bonding allow the dissolution of perovskite precursors. The interaction further enables the fast transformation of the precursor solution to a high-purity perovskite phase. Most importantly, the residual MAAc can in situ anchor the GB and effectively passivate the defect. The passivation mitigates interfacial voids and trap sites which aid in ionic migration, thus avoiding hysteresis behavior. We think that symptomatically designed ILs with different functions can accelerate the large-scale conversion of perovskite photovoltaics.

\section{Materials and Methods}

4.1. Materials. Lead iodide $\left(\mathrm{PbI}_{2}, 99.99 \%\right)$ was purchased from TCI. Spiro-OMeTAD was purchased from Youxuan Tech, China. Methylamine hydrochloride (MACl), methylammonium iodide (MAI), caesium iodide (CsI, 99.999\%), formamidinium iodide (FAI), and methylammonium bromide $(\mathrm{MABr})$ were purchased from Greatcell Solar. Chlorobenzene (CB, anhydrous), $N, N$-dimethylformamide (DMF, anhydrous), methylamine solution ( $\mathrm{MA}, 33 \%$ in $\mathrm{H}_{2} \mathrm{O}$ ), ethylic acid (HAc, 99\%), butylamine hydrochloride (BACl, 99.99\%), ethylamine solution (EA), butylamine solution (BA), propylamine, formic acid, propanoic acid, and nbutyric acid were purchased from Sigma-Aldrich. All the materials were used without further purification.

4.2. Synthesis of Ionic Liquids (ILs). MAFa, MAAc, MAPa, and $\mathrm{MABa}$ were synthesized by reaction of methylamine with the corresponding carboxylic acid. EAAc, BAAc, and PAAc were synthesized by reaction of acetic acid with the corresponding amine.

4.2.1. MAFa. At $-16^{\circ} \mathrm{C}, 15 \mathrm{ml}$ of formic acid was first diluted with $62.5 \mathrm{ml}$ of anhydrous methanol, followed by slowly adding it to a round-bottom flask containing $62.5 \mathrm{ml}$ of methylamine (33\% ethanol solution) and $25 \mathrm{ml}$ of absolute ethanol, which was stirred for $2 \mathrm{~h}$. The excess solvent is evaporated away with a rotary evaporator at $55^{\circ} \mathrm{C}$ to obtain the product MAFa.

4.2.2. MAAc. Acetic acid (glacial, $30.6 \mathrm{ml}, 0.654 \mathrm{~mol}$, Fisher Scientific) and methylamine $(55.6 \mathrm{ml}, 0.982 \mathrm{~mol}, 40 \%$ in ethanol, Aldrich) were stirred in a $500 \mathrm{ml}$ round-bottom flask for $2 \mathrm{~h}$ (ice bath) [23]. Afterwards, the liquid chemical MAAc was obtained by rotary evaporation at $80^{\circ} \mathrm{C}$ for 1 hour. The liquid product was put into a refrigerator for 2 hours to crystallize. The crystallized product was washed 3-5 times with ether for further purification; then, it was dissolved in ethanol and the excess liquid was distilled off with a rotary evaporator to obtain an ionic liquid product at $80^{\circ} \mathrm{C}$ for $1 \mathrm{~h}$. Finally, the liquid product was cooled down to room temperature before use. MAPa, MABa, EAAc, BAAc, and PAAc have the same synthesis method.

4.3. Preparation of MAAc Precursor Solution. $\mathrm{PbI}_{2}$ and MAI were mixed in MAAc $(400 \mathrm{mg} / \mathrm{ml})$ or DMF $(400 \mathrm{mg} / \mathrm{ml})$ by 
reaction at $60^{\circ} \mathrm{C}$ for 6 hours to obtain perovskite precursor solution. The molar ratio for $\mathrm{PbI}_{2}: \mathrm{MAI}$ is $1: 1$. And $\mathrm{PbI}_{2}$, MAI, and FABr were mixed in MAAc $(400 \mathrm{mg} / \mathrm{ml})$ by reaction at $60^{\circ} \mathrm{C}$ for 12 hours to get mixed cationic precursor solution. The molar ratio for $\mathrm{PbI}_{2}: \mathrm{MAI}: \mathrm{FABr}$ is $5: 4: 1$.

4.4. Device Fabrication. ITO glass substrates were cleaned with detergent, deionized water, acetone, and isopropanol, in sequence, then dried in an oven at $120^{\circ} \mathrm{C}$ for 30 minutes, and treated with ultraviolet ozone for 15 minutes. $\mathrm{SnO}_{2}$ was deposited on an ITO substrate at $3000 \mathrm{rpm}$ for $30 \mathrm{~s}$ and then annealed at $150^{\circ} \mathrm{C}$ for 30 minutes. Perovskite precursor solution was deposited on the $\mathrm{SnO}_{2}$ substrate at $4000 \mathrm{rpm}$ for $20 \mathrm{~s}$ at a constant temperature under ambient conditions. After annealing for $5 \mathrm{~min}$, Spiro-OMeTAD in $\mathrm{CB}$ solution $\left(72.6 \mathrm{mg} \mathrm{ml}^{-1}\right.$ ) with $17.5 \mu \mathrm{l}$ of lithium bistrifluoromethylsulfonate (LiTFSI) and $29 \mu \mathrm{l}$ of 4-tert-butylpyridine was deposited on the perovskite layer by spin coating at $4000 \mathrm{rpm}$ for 30 s. Finally, $\mathrm{MoO}_{3}(5 \mathrm{~nm})$ and $\mathrm{Au}(100 \mathrm{~nm})$ were sequentially deposited on the hole transport layer (vacuum is 1.1 $\left.\times 10^{-4} \mathrm{~Pa}\right)$.

4.5. Device Characterization. All the devices were tested in an $\mathrm{N}_{2}$-filled glovebox using a Keithley 2400 source meter under a simulated AM1.5G spectrum and a solar simulator (Enli Tech, Taiwan). The light intensity was calibrated to be $100 \mathrm{~mW} \mathrm{~cm}^{-2}$ using a NIST-certified monocrystalline Si solar cell (Newport 532 ISO1599). The device performance parameters were calculated from the current-voltage curves of the photovoltaic device under illumination. No protocol for preconditioning the device before its characterization was followed. The active area of the device is $0.05 \mathrm{~cm}^{2}$, and a black mask of $2.5 \times 2 \mathrm{~mm}^{2}$ is used to fix the effective area of the device during the test. The external quantum efficiency of the device is characterized by the EQE measurement system (Enli Tech).

4.6. Lifetime Characterization. (1) For humidity stability characterization, the perovskite films or devices were placed in ambient air and 30\%-80\% relative humidity at room temperature. (2) For thermal stability characterization, perovskite films or devices are continuously heated at a temperature of $85^{\circ} \mathrm{C}$ in an $\mathrm{N}_{2}$-filled glovebox. (3) For light soaking stability characterization, the light intensity was 1sun AM1.5G illumination, and the device temperature was kept at room temperature $\left(25^{\circ} \mathrm{C}\right)$. The operational stability of devices was characterized at the MPP through a sunlight simulator with AM1.5G light in an inert gas glovebox for $500 \mathrm{~h}$.

4.7. Characterization. XPS was measured with a PHI 5000 VersaProbe III with a microfocused scanning Al K $\alpha$ X-ray source. The S K-edge ( $2472 \mathrm{eV})$ XAFS spectrum of the sample was measured at the beamline (4B7A) of the Beijing Synchrotron Radiation Facility (BSRF), Institute of High Energy Physics (IHEP), Chinese Academy of Sciences (CAS). Atomic force microscope images including morphology and conductivity were obtained using a Park XE7 in a noncontact mode. SEM images of the samples were taken by Hitachi S$3400 \mathrm{~N}$ SEM. The XRD of the sample was characterized by a
Smart Lab diffractometer from Japan. The Fourier transform infrared spectroscopy (FTIR) of the sample is characterized by an IR spectrometer instrument (Thermo, Nicolet 6700). The sample style is powder. ${ }^{1} \mathrm{H}$ NMR $(600 \mathrm{MHz})$ was characterized in deuterated DMSO- $d_{6}$. Transmission electron microscopy (TEM) images were obtained with JEOL2100 from Japan. The capacitance-voltage $(C-V)$ spectrum was recorded with a Zahner Zennium electrochemical workstation at a frequency of $1 \mathrm{kHz}$ for extracting $V_{\mathrm{b}}$. TGA spectra were obtained using the thermogravimetric analyzer TA Q500 with a flow rate of $20 \mathrm{ml} \mathrm{min}^{-1}$. The temperature is set from 25 to $800^{\circ} \mathrm{C}$ at a rate of $10^{\circ} \mathrm{C} \mathrm{min}^{-1}$.

4.8. Grazing Incidence Wide-Angle X-Ray Scattering (GIWAXS). GIWAXS was characterized at the beamline BL14B1 of the Shanghai Synchrotron Radiation Facility (SSRF). The sample was tested with an X-ray beam of $\lambda=$ $0.68877 \AA$ at an incident angle of $0.20^{\circ}$ for $400 \mathrm{~s}$, and the scattered light was detected with MarCCD at a distance $\sim 746 \mathrm{~mm}$ vertically from the sample. The MAAc and DMF perovskite precursor solution is firstly spin coated on a $\mathrm{Si} / \mathrm{SnO}_{2}$ substrate at room temperature, respectively. An oily-like noncrystalline perovskite film is obtained after spin coating. Then, the film is placed on a room temperature sample stage, and the GIWAXS measurement is triggered and the temperature of the sample stage is raised simultaneously.

4.9. X-Ray Absorption Spectroscopy (XAS) Measurements. The XAFS spectra of the $\mathrm{Pb} \mathrm{L3}$ edge $(13035 \mathrm{eV})$ for precursor solution were characterized at the $1 \mathrm{~W} 1 \mathrm{~B}$ beamline of the Beijing Synchrotron Radiation Facility (BSRF). It is provided with a double $\mathrm{Si}$ (111) monochromator which was used to monochromatize the X-ray white beam. Spectral data were processed and analyzed using Athena [Ravel, B., Newville, M., 2005. ATHENA, ARTEMIS, HEPHAESTUS: data analysis for Xray absorption spectroscopy using IFEFFIT. J. Synchrotron Radiat. 12, 537e541.].

4.10. Transient Absorption Spectroscopy. Transient absorption (TA) properties of the film with different functional layers were measured using a Helios setup, where a nondegenerate pump-probe configuration was applied to probe the transient dynamics in a femtosecond to nanosecond time region (50 fs-7 ns). An optical parametric amplifier (OPerA Solo), pumped by a $1 \mathrm{kHz}$ regenerative amplifier (Coherent Libra, $800 \mathrm{~nm}, 50 \mathrm{fs}, 4 \mathrm{~mJ}$ ), was used to generate pump pulses. To seed the amplifier, a mode-locked Ti-sapphire oscillator (Coherent Vitesse, $80 \mathrm{MHz}$ ) was used. The laser from the regenerative amplifier was directly used for the pump at $800 \mathrm{~nm}$, while a beta barium borate (BBO) crystal was used to double the frequency of $800 \mathrm{~nm}$ for the pump at $400 \mathrm{~nm}$. White light continuum was applied as the probe pulses, which were formed by $800 \mathrm{~nm}$ femtosecond pulses via a sapphire plate $(2 \mathrm{~mm})$ for the $400-800 \mathrm{~nm}$ region.

4.11. Activation Energy Measurement of Ion Migration. The sample was measured on a copper substrate with temperature control by a heater and injected liquid $\mathrm{He}$ in the Lakeshore Probe Station under vacuum $\left(1.1 \times 10^{-4} \mathrm{~Pa}\right)$. The 
current was detected with Keithley 4200-SCS at $150 \mathrm{~s}$ after the voltage is switched on. It is worth noting that the device is first cooled to room temperature and then programmed to a predetermined temperature.

\section{Conflicts of Interest}

The authors declare that there is no conflict of interest regarding the publication of this article.

\section{Authors' Contributions}

Y.C. and W.H. had the idea for and designed the experiments. Y.C. and W.H. supervised the work. L.C., T.N., H.G., and Q.W. carried out the device fabrication and characterizations. Q.W. and G.X. carried out TA measurements. J.Z., S.Z., and H.G. conducted the XAFS measurements and analyzed the data. W.H., Y.Y., and X.G. carried out GIWAXS measurements. Z.Z. and X.H. carried out the TEM measurements. C.P. and H.L. carried out c-AFM measurements. X.L. and J.F. carried out activation energy and ion conductivity measurements. The first draft of the manuscript was written by L.C., T.N., Y.C. Data analysis and major revisions were completed by Y.C., Y.X., L.F., L.S., C.R., and W.H. Lingfeng Chao, Tinting Niu, Hao Gu, and Yingguo Yang contributed equally to this work.

\section{Acknowledgments}

This work was financially supported by the Natural Science Foundation of China (Grants 51972172, 61705102, and 91833304), the Natural Science Basic Research Plan in Shaanxi Province of China (2019JM-326), the Young 1000 Talents Global Recruitment Program of China, and the Fundamental Research Funds for the Central Universities. This work also was financially supported by the National Key Research and Development Program of China (grant no. 2017YFA0403400).

\section{Supplementary Materials}

Figure S1: morphology of thin films. Figure S2: scheme image of preparation of the perovskite film. Figure S3: long-term stability of MAAc perovskite films in ambient air for even 2 years under humidity of $30 \%-80 \%$. Figure S4: thermal $\left(85^{\circ} \mathrm{C}\right)$ and light (1-sun AM1.5G illumination) stability of MAAc and DMF perovskite films in an $\mathrm{N}_{2}$-filled glovebox. Figure S5: TGA spectra of MAAc and DMF perovskite powder. Figure S6: air stability of PSCs. Figure S7: light soaking stability of PSCs. Figure S8: the experimental setup for in situ GIWAXS characterization. Figure S9: a transparent oily-like noncrystalline MAAc perovskite film. Figure S10: time evolutions of peak positions for the (110) crystal plane. Figure S11: time evolutions of the full width at half maximum (FWHM) for the (110) crystal plane through multipeak mode fitting. Figure S12: time evolutions of peak areas for the (110) crystal plane through multipeak mode fitting. Figure S13: the azimuthal distribution mapping by radial integration of the (110) diffraction rings of MAAc and DMF perovskite films. Figure S14: the azimuthal distribution mapping by radial integration of the (110) diffraction rings of time evolution of MAAc and DMF perovskite films. Figure S15: FTIR spectra of MAAc-based perovskite powder, MAAc+PbI2 powder from PbI2@MAAc solution, and pure MAAc solvent. Figure S16: the X-ray photoelectron spectroscopy (XPS) spectra of $\mathrm{Pb}$ (4f) of MAAc- and DMF-based PbI2 films. Figure S17: Raman spectra of the MAAc-based PbI2 film. Figure S18: the bulk trap state density of MAAc and DMF perovskite films calculated from TA spectra. Figure S19: defect state density of MAAc perovskite, measured by capacitancevoltage $(C-V)$ with the device structure of $\mathrm{ITO} / \mathrm{SnO}_{2} /$ perovskite/Spiro-OMeTAD/MoO $3 / \mathrm{Au}$. Figure S20: the dark current density of the MAAc and DMF perovskite devices with the structure of ITO/SnO $/$ /perovskite/Spiro-OMeTAD/MoO$/$ Au. Figure S21: admittance spectra of MAAc and DMF perovskite devices with the structure of $\mathrm{ITO} / \mathrm{SnO}_{2} /$ perovskite/Spiro-OMeTAD $/ \mathrm{MoO}_{3} / \mathrm{Au}$, measured at room temperature. Figure S22: transient absorption spectra and carrier dynamics. Figure S23: transient absorption spectra and carrier dynamics. Table S1: summary of performances of the reported best-performing MAPbI3 PSCs. Table S2: the device parameters of PSCs based on different scanning directions. Table S3: TA decay time ( $\tau$ TA) and the estimated hole transfer efficiency $(\eta)$ from the TA results. Table S4: TA decay time ( $\tau \mathrm{TA})$ and the estimated electron transfer efficiency ( $\eta$ ) from the TA results. (Supplementary Materials)

\section{References}

[1] “Best research-cell efficiency chart," NREL, 2019, https://www .nrel.gov/pv/cell-efciency.html.

[2] Q. Guo, J. Wu, Y. Yang et al., "High-performance and hysteresis-free perovskite solar cells based on rare-earthdoped $\mathrm{SnO}_{2}$ Mesoporous scaffold," Research, vol. 2019, article 4049793, 13 pages, 2019.

[3] J.-P. Correa-Baena, A. Abate, M. Saliba et al., "The rapid evolution of highly efficient perovskite solar cells," Energy \& Environmental Science, vol. 10, no. 3, pp. 710-727, 2017.

[4] Q. Jiang, Y. Zhao, X. Zhang et al., "Surface passivation of perovskite film for efficient solar cells," Nature Photonics, vol. 13, no. 7, pp. 460-466, 2019.

[5] N.-G. Park and K. Zhu, "Scalable fabrication and coating methods for perovskite solar cells and solar modules," Nature Reviews Materials, vol. 5, no. 5, pp. 333-350, 2020.

[6] L. Wang, H. Zhou, J. Hu et al., "A $\mathrm{Eu}^{3+}-\mathrm{Eu}^{2+}$ ion redox shuttle imparts operational durability to $\mathrm{Pb}-\mathrm{I}$ perovskite solar cells," Science, vol. 363, no. 6424, pp. 265-270, 2019.

[7] R. Wang, J. Xue, K. L. Wang et al., "Constructive molecular configurations for surface-defect passivation of perovskite photovoltaics," Science, vol. 366, no. 6472, pp. 1509-1513, 2019.

[8] D. Luo, W. Yang, Z. Wang et al., "Enhanced photovoltage for inverted planar heterojunction perovskite solar cells," Science, vol. 360, no. 6396, pp. 1442-1446, 2018.

[9] M. Li, L. Meng, Y. Yang et al., "High-efficiency robust perovskite solar cells on ultrathin flexible substrates," Nature Communications, vol. 7, no. 1, article 10214, 2016.

[10] T. Bu, J. Li, F. Zheng et al., "Universal passivation strategy to slot-die printed $\mathrm{SnO}_{2}$ for hysteresis-free efficient flexible perovskite solar module," Nature Communications, vol. 9, no. 1, article 4609, 2018. 
[11] D. Yang, R. Yang, K. Wang et al., "High efficiency planar-type perovskite solar cells with negligible hysteresis using EDTAcomplexed $\mathrm{SnO}_{2}$," Nature Communications, vol. 9, no. 1, article 3239, 2018.

[12] N. Jeon, J. Noh, Y. Kim, W. S. Yang, S. Ryu, and S. I. Seok, “Solvent engineering for high-performance inorganic-organic hybrid perovskite solar cells," Nature Materials, vol. 13, no. 9, pp. 897-903, 2014.

[13] M. D. Xiao, F. Huang, W. Huang et al., "A Fast DepositionCrystallization Procedure for Highly Efficient Lead Iodide Perovskite Thin-Film Solar Cells," Angewandte Chemie, vol. 126, no. 37, pp. 10056-10061, 2014.

[14] S. Bai, P. Da, C. Li et al., "Planar perovskite solar cells with long-term stability using ionic liquid additives," Nature, vol. 571, no. 7764, pp. 245-250, 2019.

[15] X. Zheng, B. Chen, J. Dai et al., "Defect passivation in hybrid perovskite solar cells using quaternary ammonium halide anions and cations," Nature Energy, vol. 2, no. 7, 2017.

[16] N. K. Noel, S. N. Habisreutinger, B. Wenger et al., "A low viscosity, low boiling point, clean solvent system for the rapid crystallisation of highly specular perovskite films," Energy \& Environmental Science, vol. 10, no. 1, pp. 145-152, 2017.

[17] K. Wang, C. Wu, Y. Hou et al., "A nonionic and low-entropic $\mathrm{MA}(\mathrm{MMA}) \mathrm{nPbI}_{3}$-ink for fast crystallization of perovskite thin films," Joule, vol. 4, no. 3, pp. 615-630, 2020.

[18] M. Jung, S. G. Ji, G. Kim, and S. I. Seok, "Perovskite precursor solution chemistry: from fundamentals to photovoltaic applications," Chemical Society Reviews, vol. 48, no. 7, pp. 20112038, 2019.

[19] Z. Lei, B. Chen, Y.-M. Koo, and D. R. MacFarlane, "Introduction: ionic liquids," Chemical Reviews, vol. 117, no. 10, pp. 6633-6635, 2017.

[20] D. T. Moore, K. W. Tan, H. Sai, K. P. Barteau, U. Wiesner, and L. A. Estroff, "Direct crystallization route to methylammonium lead iodide perovskite from an ionic liquid," Chemistry of Materials, vol. 27, no. 9, pp. 3197-3199, 2015.

[21] N. Cho, F. Li, B. Turedi et al., "Pure crystal orientation and anisotropic charge transport in large-area hybrid perovskite films," Nature Communications, vol. 7, no. 1, article 13407, 2016.

[22] S. Öz, J. Burschka, E. Jung et al., "Protic ionic liquid assisted solution processing of lead halide perovskites with water, alcohols and acetonitrile," Nano Energy, vol. 51, no. 5, pp. 632-638, 2018.

[23] L. Chao, Y. Xia, B. Li, G. Xing, Y. Chen, and W. Huang, "Room-temperature molten salt for facile fabrication of efficient and stable perovskite solar cells in ambient air," Chem, vol. 5, no. 4, pp. 995-1006, 2019.

[24] H. Ren, S. Yu, L. Chao et al., "Efficient and stable RuddlesdenPopper perovskite solar cell with tailored interlayer molecular interaction," Nature Photonics, vol. 14, no. 3, pp. 154-163, 2020.

[25] L. Chao, T. Niu, Y. Xia, X. Ran, Y. Chen, and W. Huang, "Efficient and stable low-dimensional Ruddlesden-Popper perovskite solar cells enabled by reducing tunnel barrier," The Journal of Physical Chemistry Letters, vol. 10, no. 6, pp. 1173-1179, 2019.

[26] Y. Zheng, T. Niu, J. Qiu et al., "Oriented and uniform distribution of Dion-Jacobson phase perovskites controlled by quantum well barrier thickness," Solar RRL, vol. 3, no. 9, article 1900090, 2019.

[27] J. Qiu, Y. Xia, Y. Chen, and W. Huang, "Management of Crystallization Kinetics for Efficient and Stable Low-Dimensional
Ruddlesden-Popper (LDRP) Lead-Free Perovskite Solar Cells," Advanced Science, vol. 6, no. 1, article 1800793, 2019.

[28] X. Li, W. Zhang, Y. C. Wang, W. Zhang, H. Q. Wang, and J. Fang, "In-situ cross-linking strategy for efficient and operationally stable methylammoniun lead iodide solar cells," Nature Communications, vol. 9, no. 1, article 3806, 2018.

[29] A. Sharenko, C. Mackeen, L. Jewell, F. Bridges, and M. F. Toney, "Evolution of Iodoplumbate complexes in methylammonium lead iodide perovskite precursor solutions," Chemistry of Materials, vol. 29, no. 3, pp. 1315-1320, 2017.

[30] B. Li, D. Binks, G. Cao, and J. Tian, "Engineering halide perovskite crystals through precursor chemistry," Small, vol. 15, no. 47, article 1903613, 2019.

[31] M. I. Saidaminov, A. L. Abdelhady, G. Maculan, and O. M. Bakr, "Retrograde solubility of formamidinium and methylammonium lead halide perovskites enabling rapid single crystal growth," Chemical Communications, vol. 51, no. 100, pp. 17658-17661, 2015

[32] Z. Liu, L. Qiu, E. J. Juarez-Perez et al., "Gas-solid reaction based over one-micrometer thick stable perovskite films for efficient solar cells and modules," Nature Communications, vol. 9, no. 1, article 3880, 2018.

[33] M. Qin, K. Tse, T. K. Lau et al., "Manipulating the mixedperovskite crystallization pathway unveiled by in situ GIWAXS," Advanced Materials, vol. 31, no. 25, article 1901284, 2019.

[34] Z. K. Wang, M. Li, Y. G. Yang et al., "High efficiency Pb-In binary metal perovskite solar cells," Advanced Materials, vol. 28, no. 31, pp. 6695-6703, 2016.

[35] Y. Zong, Y. Zhou, Y. Zhang et al., "Continuous grainboundary functionalization for high-efficiency perovskite solar cells with exceptional stability," Chem, vol. 4, no. 6, pp. 14041415, 2018.

[36] Y. Li, W. Zhou, Y. Li et al., "Unravelling degradation mechanisms and atomic structure of organic-inorganic halide perovskites by Cryo-EM,” Joule, vol. 3, no. 11, pp. 2854-2866, 2019.

[37] D. Y. Son, J. W. Lee, Y. J. Choi et al., "Self-formed grain boundary healing layer for highly efficient $\mathrm{CH}_{3} \mathrm{NH}_{3} \mathrm{PbI}_{3}$ perovskite solar cells," Nature Energy, vol. 1, no. 7, article 16081, 2016.

[38] Y. Li, J. Shi, J. Zheng et al., "Acetic acid assisted crystallization strategy for high Efficiency and long-term stable perovskite solar cell," Advanced Science, vol. 7, no. 5, article 1903368, 2020.

[39] J. Xing, Q. Wang, Q. Dong, Y. Yuan, Y. Fang, and J. Huang, "Ultrafast ion migration in hybrid perovskite polycrystalline thin films under light and suppression in single crystals," Physical Chemistry Chemical Physics, vol. 18, no. 44, pp. 3048430490, 2016.

[40] C. C. Boyd, R. Cheacharoen, T. Leijtens, and M. D. McGehee, "Understanding degradation mechanisms and improving stability of perovskite photovoltaics," Chemical Reviews, vol. 119, no. 5, pp. 3418-3451, 2019.

[41] X.-X. Yan, B. Li, H.-S. Lin et al., "Successively Regioselective Electrosynthesis and Electron Transport Property of Stable Multiply Functionalized [60]Fullerene Derivatives," Research, vol. 2020, article 2059190, 9 pages, 2020.

[42] S. G. Joglekar, M. D. Hammig, and L. J. Guo, "High-energy photon spectroscopy using all solution-processed heterojunctioned surface-modified perovskite single crystals," ACS Applied Materials \& Interfaces, vol. 11, no. 36, pp. 3339933408, 2019. 